Cómo citar este trabajo: Remond Noa, R., Múgica Aguilar, K., Alfonso-Álvarez, C., \& Martínez Murillo, J. F. (2018). Influencia de fenómenos meteorológicos y variables geográficas en el deterioro del Malecón habanero (La Habana, Cuba). Boletín de la Asociación de Geógrafos Españoles, 77, 256-282. doi: http://dx.doi.org/10.21138/bage.2541

\title{
Influencia de fenómenos meteorológicos y variables geográficas en el deterioro del Malecón habanero (La Habana, Cuba)
}

\author{
Influence of weather and geographical factors \\ in the worsening of Habana's Malecon (La Habana, Cuba)
}

\section{Ricardo Remond}

coremond@geo.uh.cu

Karen Aguilar Múgica

karenaguilarmugica83@gmail.com

Cindy Alfonso-Álvarez

CindyAlfonsoAlvarez92@gmail.com

Facultad de Geografía

Universidad de La Habana (Cuba)

\author{
Juan Francisco Martínez Murillo \\ jfmmurillo@uma.es \\ Departamento de Geografía \\ Universidad de Málaga (España)
}

\begin{abstract}
Resumen
El Malecón habanero ubicado al norte de la franja costera de la ciudad constituye uno de los espacios públicos y turísticos más importantes que existen en La Habana. Su mantenimiento y conservación se ha convertido en una urgente necesidad, aún más en el nuevo contexto del cambio climático. El presente trabajo se realizó con el objetivo de cartografiar el estado de esta


infraestructura y analizar los eventos meteorológicos y variables geográficas que más influyen en su deterioro, para lo cual se emplean los sensores remotos y el análisis espacial y estadístico en los Sistemas de Información Geográfica (SIG). La investigación se desarrolló a través de la consulta de diversas fuentes bibliográficas, mapas e imágenes de satélite de muy alta resolución espacial, que permitieron la cartografía del estado de esta infraestructura, y al mismo tiempo, diferenciar los sectores de acuerdo a los niveles de deterioro y de actuación de las variables estudiadas. Los resultados obtenidos muestran datos inéditos de gran utilidad y aplicación para el gobierno local y las entidades encargadas de su gestión y mantenimiento.

Palabras clave: zonas vulnerables; teledetección; clasificación orientada a objeto; espacios públicos; riesgos naturales.

\begin{abstract}
Located in the northside coast of La Habana, the Malecón is one of the most famous public and touristic sites from this Cuban city. Its conservation has arised as one of the most urgent issues for local managers, especially, in the current context of Climate Change. This study deals with the deterioration mapping of this urban infrastructure as well as with the analysis of the impact of meteorological events and controlling geographic factors. This mapping procedure was performed by means of the use of remote sensing and spatial and statistical analysis in GIS. Moreover, the study was conducted through the consult of references, maps and remote sensing of high spatial resolution, which let obtain the Malecon's deterioration mapping. The results are unprecedented and quite useful for local managers.
\end{abstract}

Key words: vulnerable areas; remote sensing; object based image analysis; public sites; natural hazards.

\title{
1 Historia y evolución del Malecón habanero
}

Cuba, por su condición insular, forma alargada y estrecha y con un total de $5746 \mathrm{~km}$ de costa concentra una gran parte de su población (11,3 millones) e infraestructuras económicas y de servicios, en zonas cercanas a sus costas (Comisión Nacional de Nombres Geográficos). Una de las franjas costeras de mayor importancia en el país es el entorno urbano del Malecón habanero, situado al norte de la ciudad de La Habana, constituyendo uno de los espacios públicos y turísticos de mayor importancia para la ciudad.

El primer nombre del Malecón habanero fue "Avenida del Golfo", surgido precisamente porque es asediado constantemente por la acción de la corriente del Golfo. La idea de su construcción comenzó en 1817 cuando el gobierno local autorizó el crecimiento extramuros de la ciudad, 
proceso que dio lugar a la construcción de un nuevo barrio limitado por la franja costera, con zonas recreativas a partir de 1830, como los baños de mar (Colectivo de Autores, 2006).

En 1901 comienzan las obras del Malecón y un año después se termina el primer tramo ubicado entre las calles Prado y Crespo (Figura 1). El Malecón se proyectó con grandes luminarias sobre el muro y arbolado en la ancha acera opuesta, pero la propia naturaleza del litoral habanero impuso sus condiciones al proyecto. En 1904, la Secretaria de Obras Públicas establece una ordenanza que autoriza la compra de los terrenos residuales de la construcción del Malecón, al fondo de los edificios de San Lázaro. De esta forma se permitió a los propietarios de las parcelas construir ampliaciones o nuevas edificaciones, esta vez de frente al mar. La nueva construcción devino en un área de utilización social donde la población acudía a ella para esperar la llegada de alguna embarcación destacada, desfiles, paradas, competencias deportivas, y la celebración del Carnaval (Rodríguez, 2009).

\section{Figura 1. Primer tramo del malecón (1902)}

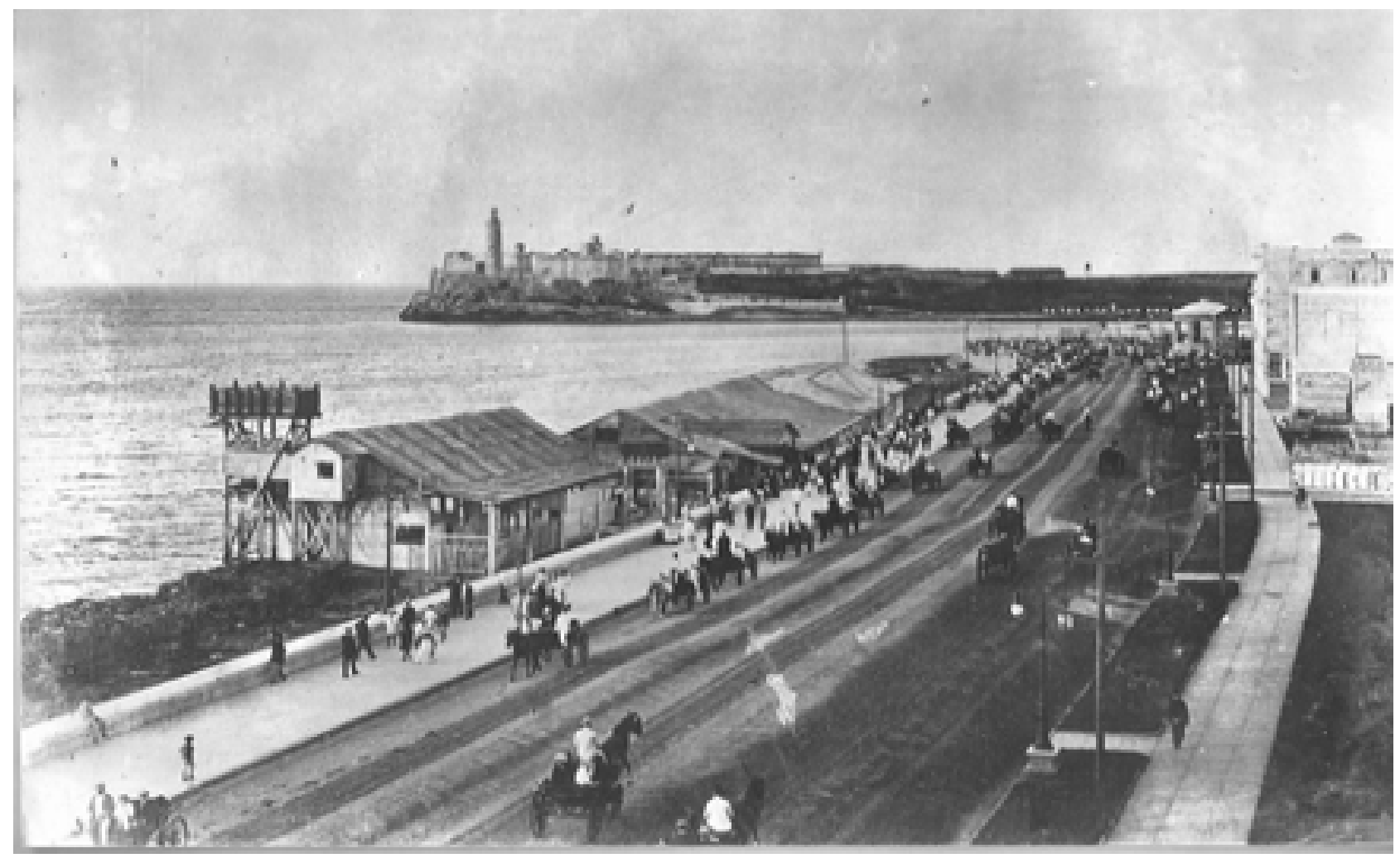

Fuente: Rodríguez (2009)

La construcción del Malecón continúa en varias fases entre 1910 y 1958: en 1919 el Malecón se extiende hasta la Calzada de Belascoaín donde se levanta el monumento al general Antonio Maceo, y de aquí hasta la calle 23 (Rodríguez, 2009); desde 23 hasta la calle $O$, construido por el gobierno de Alfredo Zayas, se finaliza en 1923; entre 1921 y 1927, se construye el tramo entre la Fortaleza de la Punta y el Puerto de la Bahía, planeado desde sus inicios con dos sentidos de 
circulación; en 1930, el presidente Gerardo Machado, continúa la obra hacia el oeste hasta la Calle G; y en 1955, el presidentes Batista lo prolongó hasta Paseo. Finalmente, la construcción del último tramo del Malecón fue propiciada por la ejecución del túnel de Calzada bajo el río Almendares en el año 1958 (Figura 2). En 1959 se acometió la tarea de llevar el Malecón hasta esa vía subterránea y enlazarlo con la Quinta Avenida (Colectivo de Autores, 2006).

Figura 2. Últimas etapas de construcción del Malecón habanero

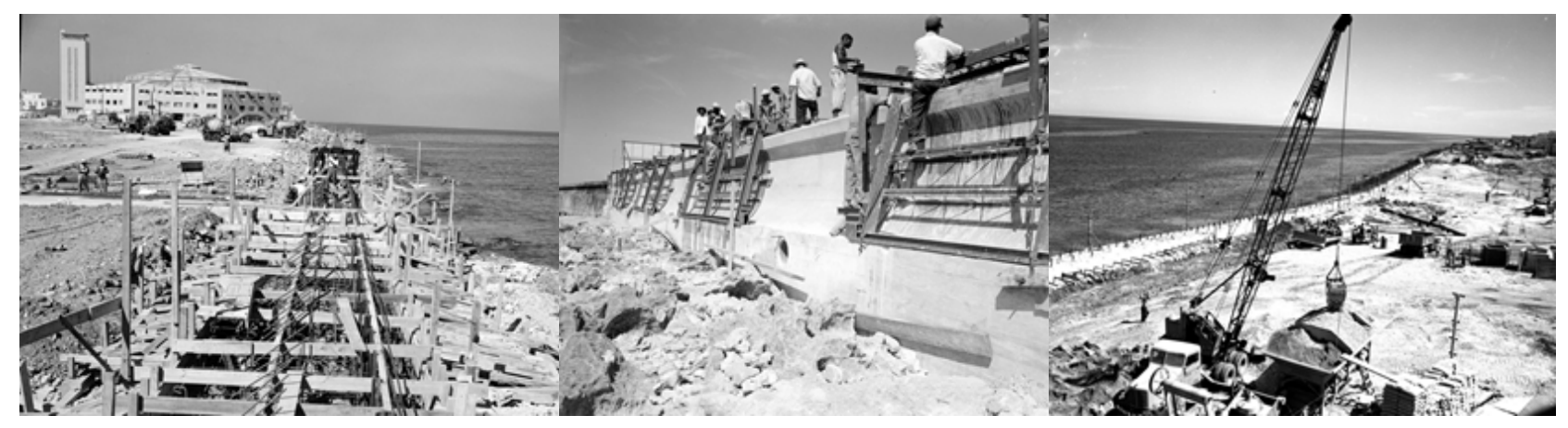

Fuente: Rodríguez (2009)

El valor del Malecón como eje de enlace entre zonas claves para el desarrollo urbano cambió el rumbo de su existencia, convirtiéndolo en una vía de tránsito rápida, que perdió el carácter de paseo costero de sus orígenes. Este carácter sería definitivo al terminar sus prolongaciones, hacia el este y el oeste a través de los túneles que lo comunicaban con otras partes de la ciudad. Dejaba así de ser un sitio para el ocio, para pasear y detenerse, y se convertía en una senda de paso donde el área de relación social se quedó limitada a la zona del muro junto al mar (Rodríguez, 2009).

De esta evolución histórica y los cambios en sus usos y su entorno, deriva el interés científico por analizar el deterioro de esta infraestructura construida en esta zona costera y los factores que intervienen en este proceso. El objetivo principal de este trabajo es cartografiar el estado del malecón habanero a partir de las técnicas de procesamiento digital de imágenes analizando los factores naturales y variables geográficas que influyen sobre el deterioro de esta infraestructura. Con estos planteamientos, la hipótesis del trabajo es la existencia de diferentes grados de deterioro del Malecón habanero resultado de un conjunto de variables geográficas que actúan de manera diferenciada en combinación con los eventos meteorológicos que afectan a este litoral. En definitiva, este trabajo aporta datos inéditos sobre el estado actual del Malecón habanero, cuáles son los tramos más deteriorados y las variables geográficas y eventos meteorológicos que más influyen sobre el mismo. El estudio tiene una clara componente aplicada, fundamentado en el empleo de las herramientas de análisis espacial y estadístico y las técnicas de procesamiento digital de imágenes de satélite presentes en los Sistema de Información Geográfica (SIG). 


\section{2 Área de estudio}

El área de estudio se corresponde con el Malecón, ubicado al norte de la provincia La Habana (Figura 3). Se trata de un largo muro de hormigón desnudo, paralelo a la línea de costa, con acera interior y una longitud de $8 \mathrm{~km}$, si bien en este trabajo se utiliza como objeto de estudio, específicamente, el sector del Malecón que se extiende desde la desembocadura del río Almendares hasta el castillo de La Punta. Actualmente, el Malecón habanero es un importante lugar de referencia de la capital cubana, por su gran importancia económica, histórica y social, trascendiendo los años para convertir a este lugar en uno de los más visitados y preferidos por la población cubana, así como por los turistas que visitan la ciudad.

Figura 3. Localización del área de estudio

Sector de los Municipios: Plaza de la Revolución, Centro Habana y Habana Vieja

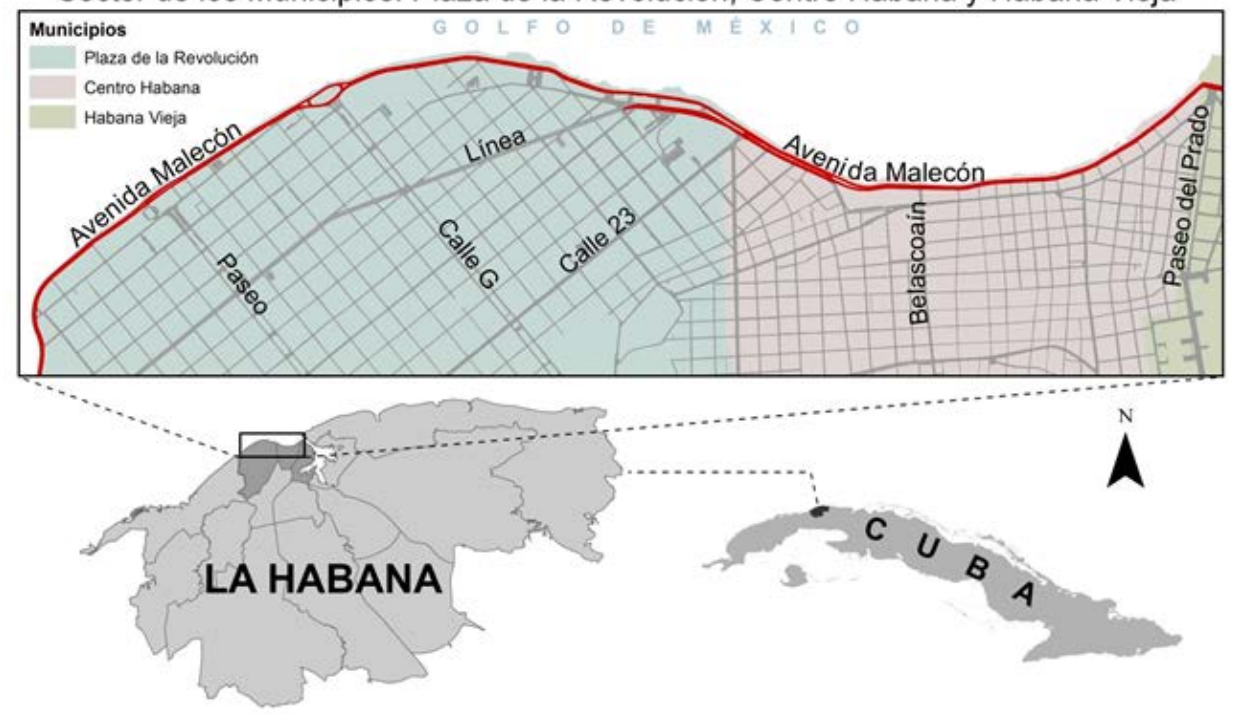

Fuente: elaboración propia

Por su posición geográfica, la isla de Cuba se encuentra sometida a los efectos de fenómenos atmosféricos tales como los ciclones tropicales, de junio a noviembre, y los frentes fríos y bajas extra-tropicales, de noviembre a abril (Díaz, 1988). Según Pérez et al. (2001), todos ellos pueden provocar penetraciones del mar e inundaciones en la zona costera, con mayor o menor afectación dependiendo de la combinación de factores físico-geográficos y meteorológicos: la dirección, velocidad y persistencia de los vientos son parámetros que contribuyen a la generación de un núcleo de ola máxima en el Golfo de México y la sostenida acumulación de las aguas en el litoral de referencia. De esta manera, resulta que la región occidental del país (la más próxima a la gran masa continental de América del Norte) posee históricamente la mayor probabilidad de ser afectada por estos fenómenos y, en particular, el tramo de costa donde se sitúa el Malecón habanero. Por ello, esta estructura está sujeta constantemente al peligro, la vulnerabilidad y el riesgo que provoca la acción destructora del mar. 
Para que concurran penetraciones del mar en La Habana y, particularmente en su Malecón, es necesario que se den condiciones específicas de velocidad, dirección, alcance y persistencia del viento que aseguren la formación de fuertes marejadas en el sudeste del Golfo de México y Estrecho de La Florida, y que al recalar en la costa noroccidental de Cuba generen un ascenso anormal del nivel del mar como consecuencia de la integración de varios factores (Pérez, Casals \& Díaz, 2001): i) la transformación de la ola por efecto del fondo marino; ii) el apilamiento de agua, generado por la acción del viento en superficie; iii) el efecto de los centros de mínima presión atmosférica, asociados a huracanes; iv) la influencia de la marea astronómica; y v) la altura de la cresta de la ola.

La disposición del litoral habanero así como la morfología de sus fondos marinos y de la zona emergida determinan que las marejadas muy fuertes de rumbo noroeste se desborden sobre la línea de costa, acumulando agua de mar sobre los arrecifes. Estos constituyen la franja de inundación temporal en la que se verifica el natural avance y retirada de las aguas traídas por las marejadas. La presencia de la estructura del Malecón en el litoral de La Habana obstaculiza este proceso, ya que fue construido sobre los arrecifes, y en algunos casos sobre material de relleno. Por consiguiente, el Malecón y la avenida que lo bordea pasaron a formar parte de la mencionada franja de inundación temporal, reduciendo el ancho del arrecife. No obstante, toda su estructura no ofrece las mismas posibilidades de penetración del mar en cada una de sus secciones debido a que se orientan y tienen características diferentes.

Habitualmente, la construcción de estas obras persigue los objetivos de embellecer el entorno y de proteger las zonas interiores contra inundaciones extremas debido a fuertes marejadas, pero se ha comprobado que en el lugar de batimiento de las olas frente a dichas estructuras, concurren procesos que generan un apilamiento anormal del agua de mar, provocando inundaciones (Pérez et al., 2001). La Figura 4 muestra el efecto del oleaje provocado por los eventos meteorológicos a su paso por el Malecón habanero.

Figura 4. Efecto del oleaje en el Malecón de La Habana

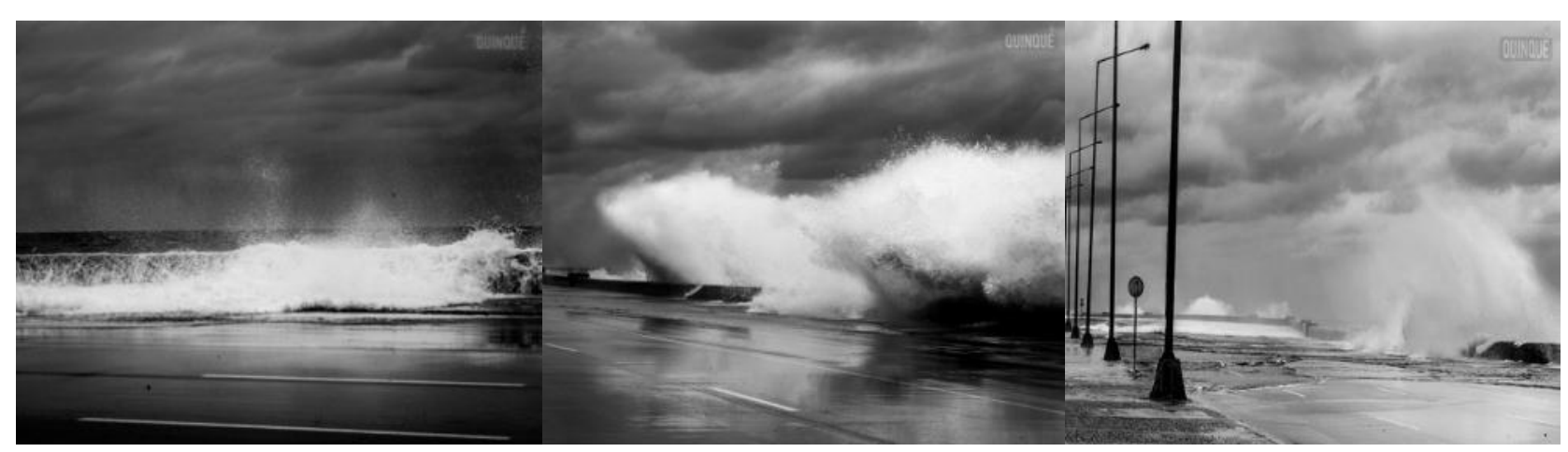

Fuente: Vázquez (2013) 
El Malecón de La Habana es un área que está expuesta a riesgos la mayor parte del año (Figura 5) En la época comprendida entre los meses de diciembre y abril, la zona es afectada por las bajas extra-tropicales y los sistemas frontales propios de la temporada invernal; mientras que entre los meses de junio y noviembre, se corresponde con la temporada ciclónica. Únicamente en el mes de mayo existe poca exposición a riesgos. De esta manera, el área de estudio constituye una zona muy vulnerable a las afecciones producidas por los fenómenos meteorológicos, y aunque algunos de ellos, como los ciclones, no sean tan frecuentes, existen otros como los frentes fríos que afectan con más regularidad al área de estudio y ocasionan daños considerables en su infraestructura.

Figura 5. Peligros naturales que inciden sobre el malecón habanero durante el año

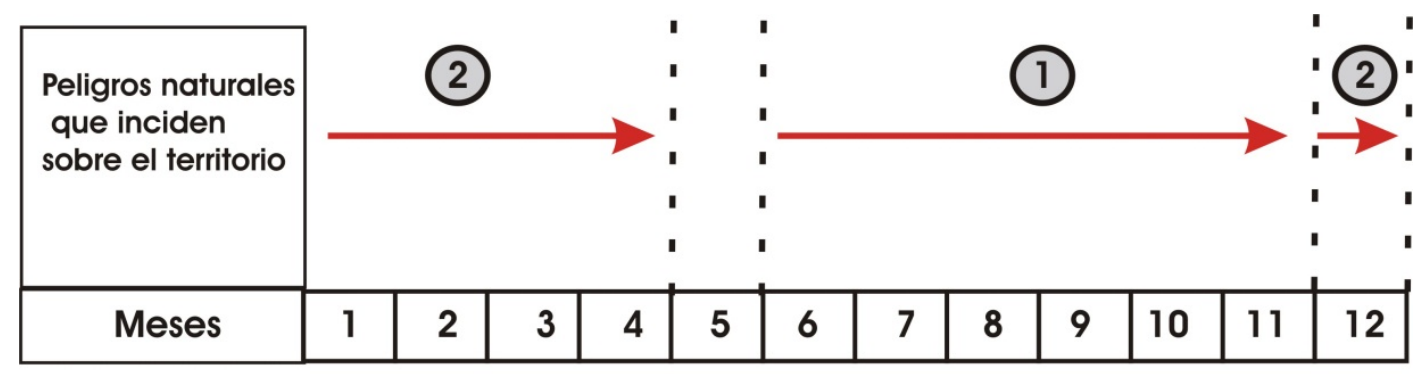

Leyenda

(1) Temporada ciclónica: depresiones, tormentas tropicales y huracanes

(2) Temporada invernal: Bajas extratropicales $y$ frentes fríos

Fuente: Rodríguez (2009)

\section{Metodología}

La aplicación de las herramientas de análisis espacial y estadístico en los SIG junto con las técnicas de procesamiento digital de imágenes representa un punto importante de este trabajo y la fuente principal de donde extraer los resultados para su análisis. La metodología diseñada es fácilmente extrapolable a otros territorios litorales y puede servir de base para diferentes investigaciones. La metodología empleada puede ser resumida en tres etapas:

i) Cartografía del estado del Malecón de La Habana.

ii) Factores que influyen en el deterioro de esta infraestructura.

iii) Diferenciación espacial del litoral habanero de acuerdo a la influencia de estos factores.

Los principales materiales utilizados fueron los siguientes: mapas topográficos nacionales de Cuba a escala 1:2000; imagen de satélite Wordview II del año 2012, con una resolución espacial de 0,5 × 0,5 m; datos meteorológicos procedentes del Instituto de Meteorología de Cuba; y otros datos de interés obtenidos mediante trabajo de campo. 


\subsection{Cartografía del estado del Malecón de La Habana}

Esta primera fase metodológica tiene su punto de partida en las técnicas de corrección geométricamente y de mejoramiento de la imagen de satélite Worldview II empleadas en este estudio. De este modo, se procedió en primer lugar a la fusión de la banda pancromática con las bandas multiespectrales (pansharpening), aplicando la técnica de regresión local. Una vez fusionadas las bandas, se realizó la corrección geométrica de la imagen. Para ello se utilizaron un total de 200 puntos de control y el Modelo Digital de Elevaciones del área de estudio, con una resolución espacial de 0,25 ×0,25m. Como resultado de este proceso se generó una imagen ortorectificada del área de estudio sobre la cual se continuó el procedimiento metodológico. Este proceso de correcciones se efectuó mediante el sistema de información geográfica Idrisi, versión 17.02 Selva.

A continuación, mediante trabajo de campo y el uso de un GPS, se efectuaron varios recorridos por el área de estudio para realizar un inventario de las zonas en donde se observaban manifestaciones de deterioro en el Malecón y las aceras interiores. Las principales manifestaciones de deterioro identificadas fueron las siguientes (Figura 6):

- Afloramiento de piedras en el hormigón (a)

- Huecos y grietas (b)

- Instalaciones hidráulicas en mal estado (c)

- Cambios en la coloración original del hormigón (resultado del humedecimiento y el crecimiento de vegetación) (d)

\section{Figura 6. Ejemplos de manifestaciones de deterioro en el Malecón de La Habana}

(a)

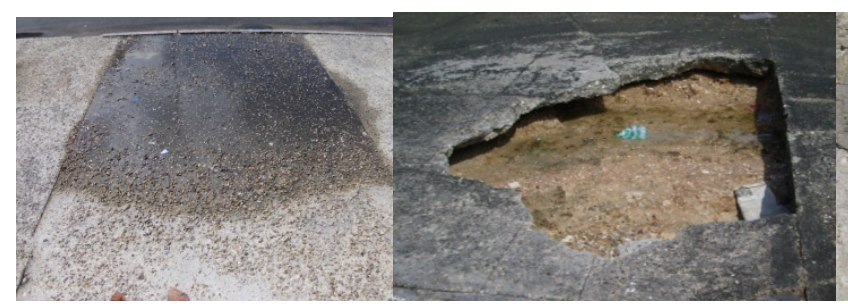

(c)

(d)

Fuente: elaboración propia

La cartografía de estos espacios fue realizada a partir del empleo de diferentes técnicas de procesamiento digital de imágenes: transformación de la imagen (Índices de vegetación), Clasificaciones multiespectrales, y Clasificación orientada a objetos.

a) Índices de vegetación 
Las técnicas de transformación de la imagen ofrecen un rango ilimitado de transformaciones posibles para la información tomada por los sensores remotos (Eastman, 2012). El fin de este grupos de técnicas operaciones entre bandas puede ser la delineación e identificación de ciertos elementos (masas de agua, formaciones rocosas, construcciones, etc.), o bien la caracterización de las distintas áreas del terreno (tipo de uso de suelo, condiciones fisicoquímicas, etc.), existiendo para cada uno de estos propósitos una serie de algoritmos y formulaciones (Olaya, 2011).

Dentro de este gran grupo de técnicas de transformación de la imagen una de las técnicas más utilizadas son los índices de vegetación. Estos índices permiten detectar la presencia de vegetación en una zona y la actividad de esta, ya que sus valores están en relación con dicha actividad. Para ello, utilizan los valores de reflectancia correspondientes a las distintas longitudes de onda, interpretando estas en relación con la actividad fotosintética (Eastman, 2012).

Para la cartografía del humedecimiento y el crecimiento de vegetación sobre superficies impermeables como el hormigón en las aceras y el muro del Malecón se emplearon los índices de vegetación de diferencia normalizada (NDVI) y el índice de vegetación Índice de vegetación de diferencia ponderada (WDVI), sugerido por Richardson y Wiegwand (Eastman, 2012). Ese último índice basado en la distancia tiene la ventaja de minimizar los efectos del fondo del suelo. Para su aplicación fue necesario el cálculo de la regresión lineal entre los valores digitales de las bandas del rojo y del infrarrojo utilizando los pixeles de las zonas sin vegetación obtenidos previamente a través de recorridos de campo con el empleo de un sistema de posicionamiento global (GPS). El WDVI (Weighted Difference Vegetation Index), se calcula a partir de la expresión (Eastman, 2012): WDVI $=\rho n-\gamma \rho r$

Donde:

$\rho n=$ reflectancia de la banda infrarroja cercana

$\rho r=$ reflectancia de la banda roja visible

$\gamma=$ pendiente de la línea de suelo

El análisis del histograma de frecuencia de los niveles digitales del índice de vegetación y las operaciones de reclasificación en el SIG utilizando el método de cortes naturales permitió identificar las zonas deterioradas en esta infraestructura (Figura 7). Estos resultados serán comentados en el apartado 4.

b) Clasificaciones multiespectrales

La clasificación multiespectral o digital es una técnica que permite agrupar los píxeles de una imagen según el valor de sus ND, haciéndoles corresponder un determinado tipo de cobertura de 
la superficie (vegetación, suelos, agua, etc.), con el fin de obtener una nueva imagen que se convertirá en un mapa temático de uso de suelo o en información estadística (Seco, 2002).

La clasificación supervisada tiene dos fases (Chuvieco, 1996):

- Fase de entrenamiento: donde el analista después de determinar los tipos de cobertura en la imagen (clases informacionales), selecciona dentro de cada una de ellas, áreas que sean representativas de la clase a que pertenecen (Seco, 2002). Estas áreas se denominan training fields (áreas de entrenamiento), a partir de las cuales el ordenador calcula los ND que definen cada una de las clases, para luego asignar el resto de los pixeles de la imagen a una de esas categorías en función de sus ND (Chuvieco, 1996).

- Fase de asignación o de clasificación: en la que cada una de las clases informacionales declaradas por el usuario, queda caracterizada por un conjunto de estadísticas, obtenidas de los valores de los ND asignados en la fase de entrenamiento (Seco, 2002). Para calcular la pertenencia de cada pixel de la imagen, a cada una de las clases informacionales declaradas existen diferentes métodos de clasificación.

Siguiendo las dos etapas anteriores a partir del trabajo de campo y con el empleo de un Sistemas de posicionamiento Global fueron tomados sitios de entrenamientos que fueran representativos de zonas donde existían manifestaciones de deterioro y en zonas donde el hormigón de las aceras y muro estaba en buen estado. A partir de esta información se generaron las firmas espectrales de ambas categorías. En la última etapa de se emplearon los clasificadores rígidos disponibles en el SIG Idrisi: (Parallelepiped classification, Minimum Distance to means classification y Maximum Likelihood classification) para obtener la cartografía de las zonas deterioradas y zonas no deterioradas) (Figura 7).

\section{c) Clasificación orientada a objetos}

El método de clasificación orientado a objeto es una técnica relativamente reciente; este tipo de clasificación se basa en la identificación de objetos, definidos como, grupos de píxeles contiguos que poseen un comportamiento similar; de manera que la variabilidad entre los píxeles que lo componen es inferior a la variabilidad entre el objeto y su entorno (Navulur, 2007).

Con el empleo de los tres módulos del SIG Idrisi se procedió a la aplicación de esta técnica de clasificación basada en los segmentos. El módulo de SEGMENTATION se empleó para crear una imagen de segmentos que tiene un comportamiento espectral similar en muchas bandas. El módulo de SEGTRAIN asigna estos segmentos a un tipo específico de cobertura terrestre para el desarrollo de los sitios de entrenamiento, por último el módulo de SEGCLASS clasifica la imagen usando un algoritmo o regla de gobierno de la mayoría, para asignar cada segmento a la clase con mayoría del mismo en la imagen de referencia (Clark Labs, 2009). 
Finalmente, en esta fase de trabajo, se procedió a la comprobación de los resultados obtenidos por cada una de las técnicas empleadas. Para ello, se realizó una nueva campaña de trabajo de campo en el área de estudio, a través de la cual, con el empleo de un GPS, se recogió una nueva nube de puntos georreferenciados para la comprobación de los resultados. A partir de ellos, se compararon los resultados obtenidos en cada una de las técnicas y se identificaron las técnicas que arrojaron los mejores resultados. Para dar continuidad al estudio se selecciona el mapa cuya técnica ofreció los mejores resultados en este caso la clasificación orientada a objetos (Figura 7).

\subsection{Determinación y a nálisis de los factores del deterioro del Malecón de La Habana}

En esta segunda etapa de la investigación, se identificaron un conjunto de factores o variables que influyen en el deterioro del Malecón de La Habana. Esta selección fue el resultado de la lectura de trabajos relacionados con el tema publicados en Weng (2012), y la consulta a especialistas del Departamento de Pronóstico del Instituto de Meteorología de Cuba. De este modo, las variables tomadas en cuanta para el estudio se resumen en la Tabla 1.

\section{Tabla 1. Factores que influyen en el deterioro del Malecón de La Habana}

\begin{tabular}{|l|l|}
\hline Factor & Método y fuente \\
\hline $\begin{array}{l}\text { Dirección y fuerza de los } \\
\text { vientos en los frentes fríos }\end{array}$ & $\begin{array}{l}\text { Rosa de los vientos predominantes (base de datos: } 22 \text { años). Fuente: } \\
\text { INSMET. }\end{array}$ \\
\hline Profundidad del mar & $\begin{array}{l}\text { MDE }(0,25 \times 0,25 \text { m) a partir del mapa topográfico nacional 1:2000. } \\
\text { Fuente: Instituto Cubano de Geodesia y Cartografía. }\end{array}$ \\
\hline Superficie del arrecife & $\begin{array}{l}\text { Foto-interpretación y digitalización de la imagen pancromática de } \\
\text { WorldView Il. Fuente: elaboración propia. }\end{array}$ \\
\hline $\begin{array}{l}\text { Distancia del Malecón a la } \\
\text { línea de costa }\end{array}$ & $\begin{array}{l}\text { Modelo de distancia a la línea de costa generado con el SIG, con } \\
\text { tamaño de píxel de 0,5xO,5m. }\end{array}$ \\
\hline $\begin{array}{l}\text { Altura del Malecón sobre } \\
\text { el nivel medio del mar. }\end{array}$ & $\begin{array}{l}\text { Representación de la diferencia de altura entre la cima del muro del } \\
\text { Malecón y el nivel medio del mar, calculada a partir del MDE. }\end{array}$ \\
\hline Orientación de la costa & $\begin{array}{l}\text { Orientación en grados, según la rosa de los vientos, de la línea de la } \\
\text { costa, obtenida a partir de la representación en formato vectorial en } \\
\text { SIG, de la línea de la costa y del muro del malecón, formando una } \\
\text { línea continua a lo largo del área de estudio. }\end{array}$ \\
\hline
\end{tabular}

Fuente: INSMET (2012), Instituto Cubano de Geodesia y Cartografía (1990), MDE (1990) y elaboración propia

Una vez definidos los factores influyentes en el deterioro del Malecón, se pasó a determinar cuál o cuáles de ellos ejercían una mayor influencia sobre dicho deterioro. Es necesario señalar que, como son los frentes fríos los fenómenos meteorológicos que inciden con mayor frecuencia en el área de estudio, se tomó la dirección de los vientos predominantes de los mismos (130-150 grados) para extraer los valores de cada variable, con vistas a conocer el comportamiento de cada una frente a las zonas deterioradas y a probar estadísticamente cuáles de ellas tienen una mayor influencia en el deterioro de esta infraestructura. Para ello, se aplicó el coeficiente de Correlación 
Biserial puntual, que se trata de un coeficiente óptimo para correlacionar una variable continua y una variable dicotómica (Cué, 1987).

El coeficiente de correlación biserial puntual $\left(r_{b p}\right)$ se obtiene de la siguiente fórmula:

$$
r_{b p}=\frac{\bar{X}_{p}-\bar{X}_{q}}{\sigma_{x}} \sqrt{p q}
$$

Dónde: $X$, es la variable continua; $Y$, es la variable dicotómica; $p$, proporción de casos de una de las dos modalidades de $Y$; $q, 1-p ; X_{p}$, media de los casos que en la variable $X$ poseen la característica $p ; X_{q}$, media de los casos que en la variable $X$ poseen la característica $q ; \sigma_{X}$, desviación típica de la variable $X$.

Este coeficiente toma los valores entre -1 y 1 . Cuanto más cerca de -1 o 1, mayor es la correlación entre las variables. Si es igual a cero significa que las variables estudiadas no están correlacionadas. El signo de rbp indica el sentido de la relación, un signo negativo indica una relación inversa, mientras que un signo positivo indica una relación directa (Cué, 1987).

\subsection{Diferenciación espacial del litoral habanero (análisis clúster)}

Las herramientas de agrupamiento de variables son ampliamente utilizadas en los estudios geográficos para establecer grupos e identificar espacios de actuación, en los últimos años son ampliamente utilizadas en estudios de corte social (Buzai, 2016), de desigualdades (Gezici \& Hewings, 2007), (Pedregal, Torres \& Zoido, 2006), de la población (Martori \& Hoberg 2008) y en estudios socioeconómicos relacionados con la distribución espacial de industrias, (Kulkarni, Paelinck, \& Stough, 2001), los servicios, el turismo (Sánchez, 2008) y las enfermedades (Wall \& Devine, 2000).

En esta etapa final de la metodología se emplearon las herramientas de agrupamiento o cluster espacial ejecutadas en ArcGIS 10.2.3 para identificar los espacios o zonas más vulnerables al deterioro se acuerdo a las semejanzas en el comportamiento de las variables analizadas (Profundidad del mar, superficie del arrecife, distancia del Malecón a la línea de costa, altura del Malecón sobre el nivel medio del mar y orientación de la costa), siguiendo la dirección de los vientos predominantes en el litoral, lo que permitió obtener dos grupos o zonas que fueron caracterizadas identificando las variables que más inciden en el deterioro.

Para representar a estas zonas fue necesaria previamente la generación de 300 perfiles siguiendo la orientación de la dirección predominante de los vientos de los frentes fríos y con una equidistancia de 10 metros entre ellos. Posteriormente mediante diversas operaciones en el SIG fue completada la base de datos de cada perfil con la información de las variables analizadas y 
finalmente se emplearon las herramientas de agrupamiento o cluster espacial para identificar los tramos del Malecón con semejanza de acuerdo al comportamiento de las variables.

\section{Resultados y discusión}

\subsection{Estado de deterioro del Malecón}

Según los análisis de la imagen de satélite Worldview II, $28.216 \mathrm{~m}^{2}$ del Malecón presentan algún rasgo de deterioro, lo cual supone un 56,9\% de su superficie. Por el contrario, solo queda poco más del 40 \% del Malecón sin presentar algún rasgo de deterioro, de los inventariados en campo y descritos previamente. Las zonas con más deterioro se ubican fundamentalmente al noroeste del sector estudiado (Figura 7), desde calle 26 hasta la calle $G$, aunque también se pueden encontrar áreas en el centro y este, destacándose algunos sectores en Malecón y calle 23 y otro sector ubicado entre Belascoaín y Vapor (frente al parque Antonio Maceo). En este Figura 7, se muestra la cartografía obtenida a partir de la clasificación orientada a objetos, que fue la técnica que mejor resultado ofreció, como se puede observar en la Tabla 2. Como se puede observar en esta tabla, a partir del método de clasificación orientado a objetos (COB), el 91,9\% de los puntos seleccionados como deteriorados se corresponden con esta categoría en la realidad, por lo que esta técnica constituye la de mejores resultados en la cartografía de las zonas con deterioro. Esta técnica de clasificación se ha revelado como una técnica bastante precisa. Así, se pone de manifiesto en estudios recientemente publicados (Oleire, et al., 2011; Moskal, et al., 2011; Hofmann, et al., 2011).

También cabe destacar el resultado del método índice de vegetación basado en la línea del suelo (WDVI), el cual resultad muy eficiente para la cartografía de un tipo especial de deterioro como es la presencia de vegetación sobre esta infraestructura. La comprobación de la cartografía obtenida se realizó a través de la selección aleatoria de 206 puntos en el área de estudio, de los cuales 94 se corresponden con zonas donde se observó algún rasgo de deterioro y los restantes 112 puntos corresponden a áreas donde no había evidencia de deterioro alguno.

Tabla 2. Comparación entre los métodos utilizados en la cartografía del deterioro del Malecón

\begin{tabular}{|l|c|c|c|c|c|c|}
\hline Validación & \multicolumn{7}{|c|}{ Técnica de procesamiento digital de imágenes utilizada } \\
\hline & NDVI & WDVI & CSP & CSM & CSMP & COB \\
\cline { 2 - 7 } & Deterioro & Deterioro & Deterioro & Deterioro & Deterioro & Deterioro \\
\hline Con deterioro & 68,1 & 88,8 & 89,8 & 83,2 & 81,4 & 91,9 \\
\hline Sin deterioro & 31,9 & 11,2 & 10,2 & 16,8 & 18,6 & 8,1 \\
\hline & 100,0 & 100,0 & 100,0 & 100,0 & 100,0 & 100,00 \\
\hline
\end{tabular}

Abreviaturas: NDVI, índice de vegetación normalizado; WDVI, índice de vegetación basado en la línea de suelo; CSP, clasificación supervisada; CSM, clasificación supervisada basada en la mínima distancia; CSMP, clasificación supervisada basada en la máxima probabilidad; COB, clasificación orienta a objeto.

Fuente: elaboración propia 
Figura 7. Distribución espacial de las zonas deterioradas del Malecón de La Habana en el sector estudiado

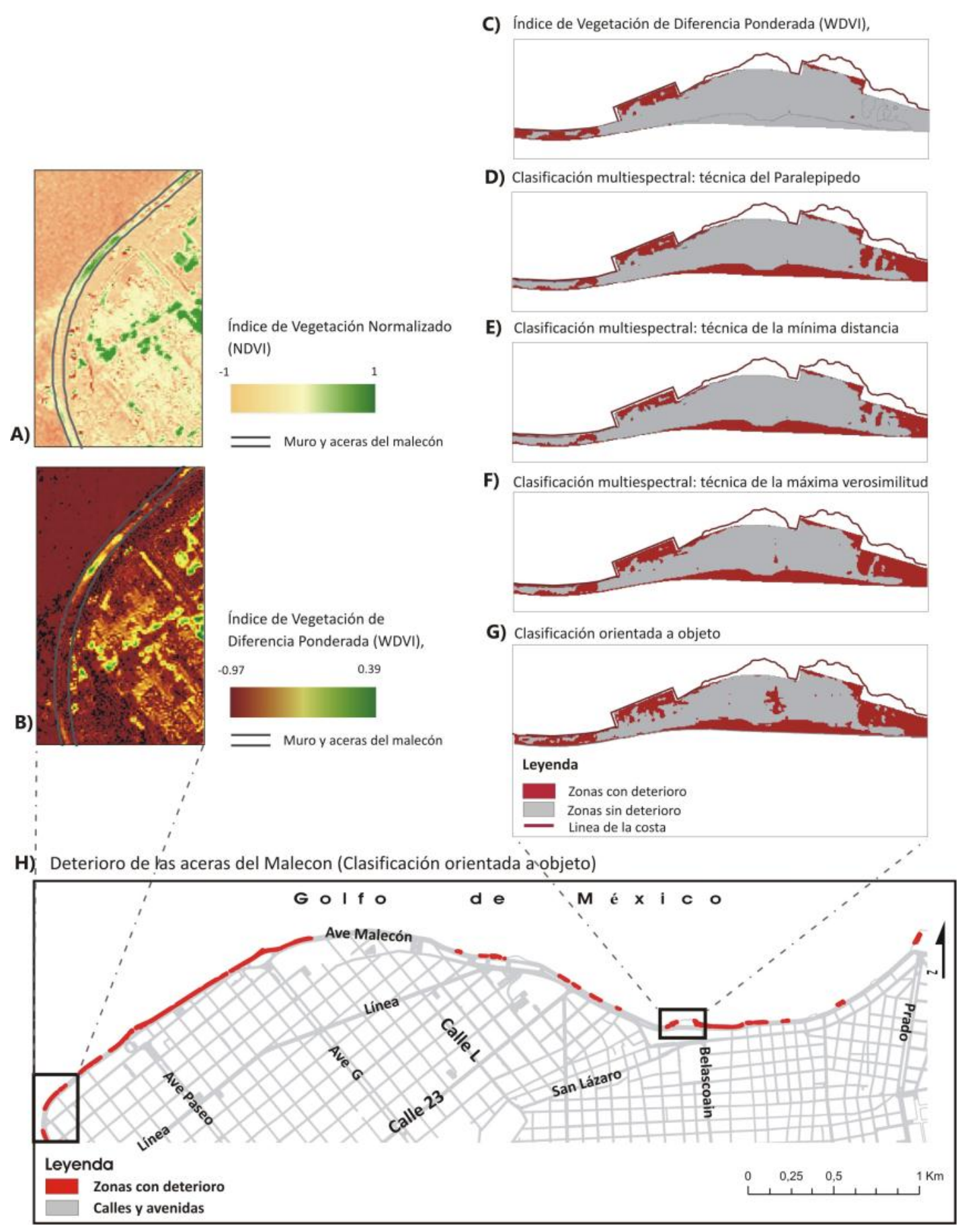

Fuente: elaboración propia

\subsection{Análisis de los factores que influyen en el deterioro del Malecón}

a) Los frentes fríos

Desde la temporada invernal 1990-1991 a la temporada invernal 2011-2012, La Habana ha sido afectada por un total de 436 frentes fríos, con un promedio de 19,8 por temporada. Teniendo en cuenta la velocidad de los vientos, el $66,7 \%$ han sido clasificados como débiles, 32,3\% como 
moderados y sólo 0,01\% como fuertes. La Figura 8 muestra la dirección dominante de los frentes fríos de las 22 temporadas estudiadas, en relación con la dirección de sus vientos.

Figura 8. Dirección dominante de los vientos desde 1990 a 2012

a) Fuerza de los vientos

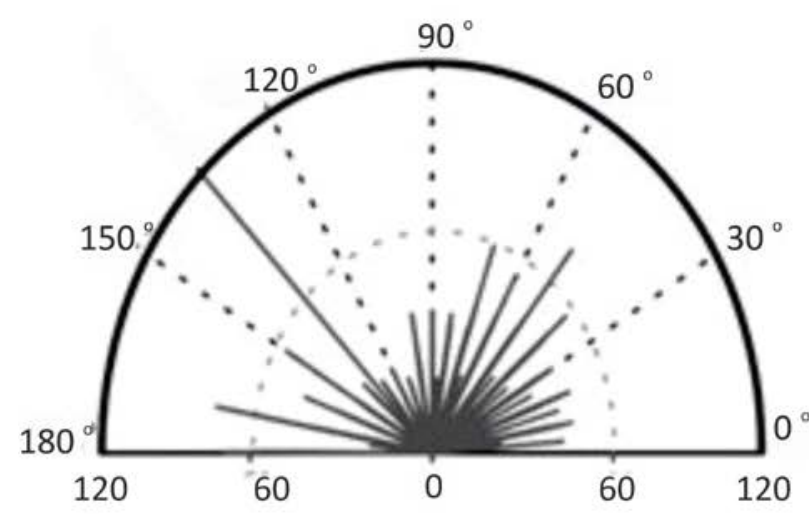

LEYENDA

- Fuerza de los vientos (en $\mathrm{km} / \mathrm{h}$ )

$60^{\circ}$ Dirección de los vientos (en grados) b) Frecuencia de los vientos

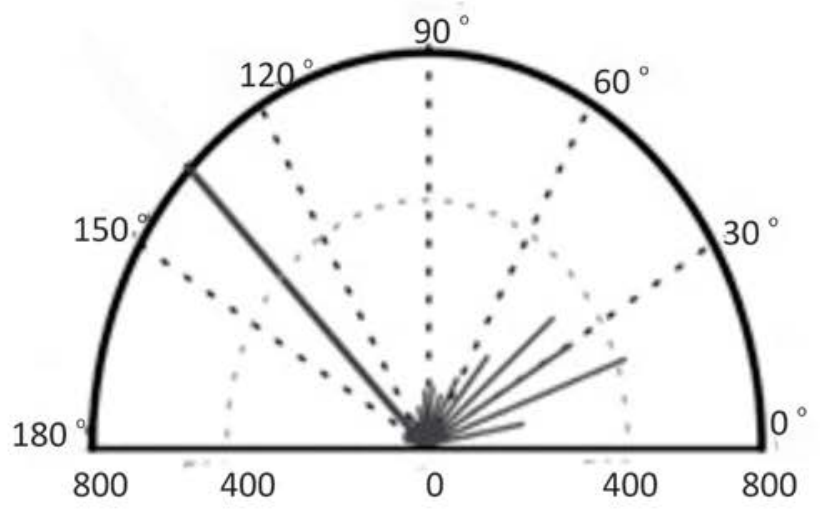

LEYENDA

- Frecuencia de los vientos (en número de veces) $60^{\circ}$ Dirección de los vientos (en grados)

Fuente: Instituto de Meteorología de Cuba (INSMET, 2012)

El análisis de la figura anterior nos revela que la mayor intensidad de los vientos tiene componente noroeste, aproximadamente entre los $130^{\circ}$ y $140^{\circ}$. En consecuencia, como se puede observar, la mayor frecuencia (cantidad de veces que el viento sopla en la misma dirección, pero sin tener en cuenta su magnitud) ocurre también en la misma dirección, lo cual confirma que esta es la dirección predominante en la entrada de los frentes fríos y que, a la vez, es la que registra los mayores valores en la fuerza de sus vientos.

\section{b) Profundidad del mar}

El análisis de la profundidad del mar a través del MDE generado nos revela que en la zona de del sector del Malecón estudiado se alcanza una mayor profundidad a menos distancia de la costa que en otros sectores. Esto tiene como consecuencias que los trenes de olas llegan con más energía Malecón, lo que podría ser una de las causas del grave deterioro de esta infraestructura. Las estadísticas generales de esta variable (Tabla 3) extraídas siguiendo la misma dirección de los vientos predominantes de los frentes fríos, nos revelan que no existen diferencias significativas en cuanto a los valores mínimos, medios y máximos obtenidos de ambas clases. Sin embargo, si se analiza el histograma de frecuencia, pueden observarse importantes diferencias (Figura 9). 
Tabla 3. Profundidad del mar frente a zonas deterioradas y no deterioradas

\begin{tabular}{|l|c|c|c|c|}
\cline { 2 - 5 } \multicolumn{1}{c|}{} & $\begin{array}{c}\text { Profundidad } \\
\text { máxima }(\mathrm{m})\end{array}$ & $\begin{array}{c}\text { Profundidad } \\
\text { mínima }(\mathrm{m})\end{array}$ & $\begin{array}{c}\text { Profundidad } \\
\text { media }(\mathrm{m})\end{array}$ & $\begin{array}{c}\text { Desviación } \\
\text { estándar }(\mathrm{m})\end{array}$ \\
\hline $\begin{array}{l}\text { Zonas } \\
\text { deterioradas }\end{array}$ & $-11,56$ & 0,00 & $-3,48$ & 2,52 \\
\hline $\begin{array}{l}\text { Zonas } \\
\text { no deterioradas }\end{array}$ & $-12,70$ & 0,00 & $-3,88$ & 2,72 \\
\hline
\end{tabular}

Fuente: elaboración propia

Figura 9. Histograma de frecuencias de la profundidad del mar frente al Malecón

a) Perfil en zonas con deterioro

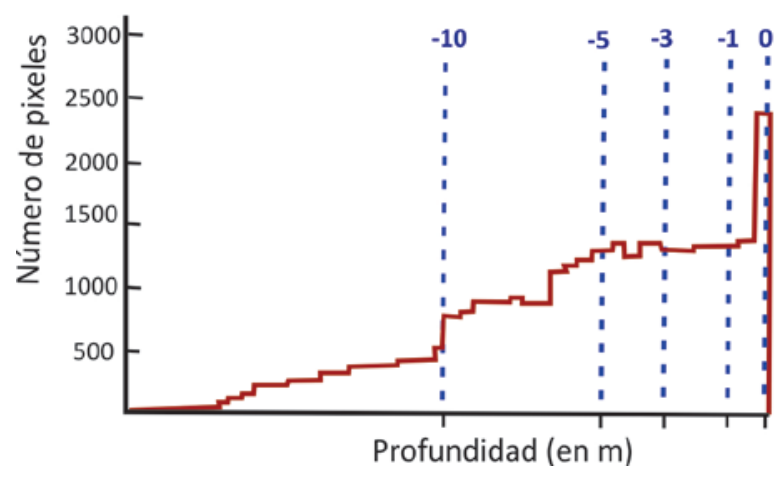

b) Perfil en zonas sin deterioro

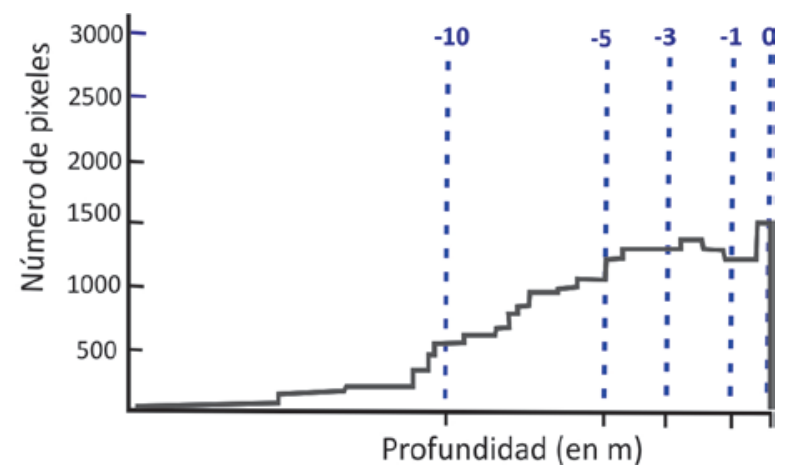

Fuente: elaboración propia

En la figura anterior se muestran los valores de profundidad extraídos de los perfiles batimétricos frente a zonas con deterioro y sin deterior en el Malecón. Es interesante resaltar que frente a las zonas con deterioro, el perfil de la costa en los primeros 20 metros más próximos a esta es menos profundo que en las zonas donde no hay deterioro, lo que pudiera traer como consecuencia que se generen olas con mayores alturas debido a la conversión de la energía cinética de la ola en energía potencial (altura). En consecuencia, las olas rompen con más altura cerca de la costa y penetran en el interior del Malecón.

\section{c) Superficie del arrecife frente al Malecón}

Frente a las zonas deterioradas, solo aflora el $18,75 \%$ del total del arrecife costero emergido (Tabla 4). Ello implica que la mayor parte de las zonas donde existe algún tipo de deterioro se encuentran desprotegidas por la inexistencia del arrecife y son estas zonas del muro las que, por tanto, reciben el embate directo del oleaje y las salpicaduras de este. De las 61 zonas o polígonos identificados con algún tipo de deterioro en las aceras del Malecón, 18 de ellos $(29,3 \%)$ no tienen arrecife en la costa frente a ellas; en este caso, el muro se convierte en la barrera de protección de la costa por lo que está sujeto de manera permanente al golpeo de las olas. En el resto de la infraestructura con signos de deterioro 71,3\% (43 polígonos), sí emerge frente a ellos el arrecife, si 
bien, en la mayor parte de ellas, el arrecife tienen unas dimensiones muy pequeñas (Figura 10), por lo que su efecto de protección se reduce.

Tabla 4. Superficie de arrecife frente al muro del Malecón

\begin{tabular}{|l|c|c|}
\cline { 2 - 3 } \multicolumn{1}{c|}{} & Superficie $\left(\right.$ en $\left.\mathrm{m}^{2}\right)$ & Superficie (en \%) \\
\hline Arrecife frente a zonas deterioradas & 7170,17 & 18,75 \\
\hline Arrecife frente a zonas sin deterioradas & 31054,30 & 81,23 \\
\hline Total & 38224,47 & 100,00 \\
\hline
\end{tabular}

Fuente: elaboración propia

Figura 10. Superficie del arrecife frente a las zonas deterioradas del Malecón

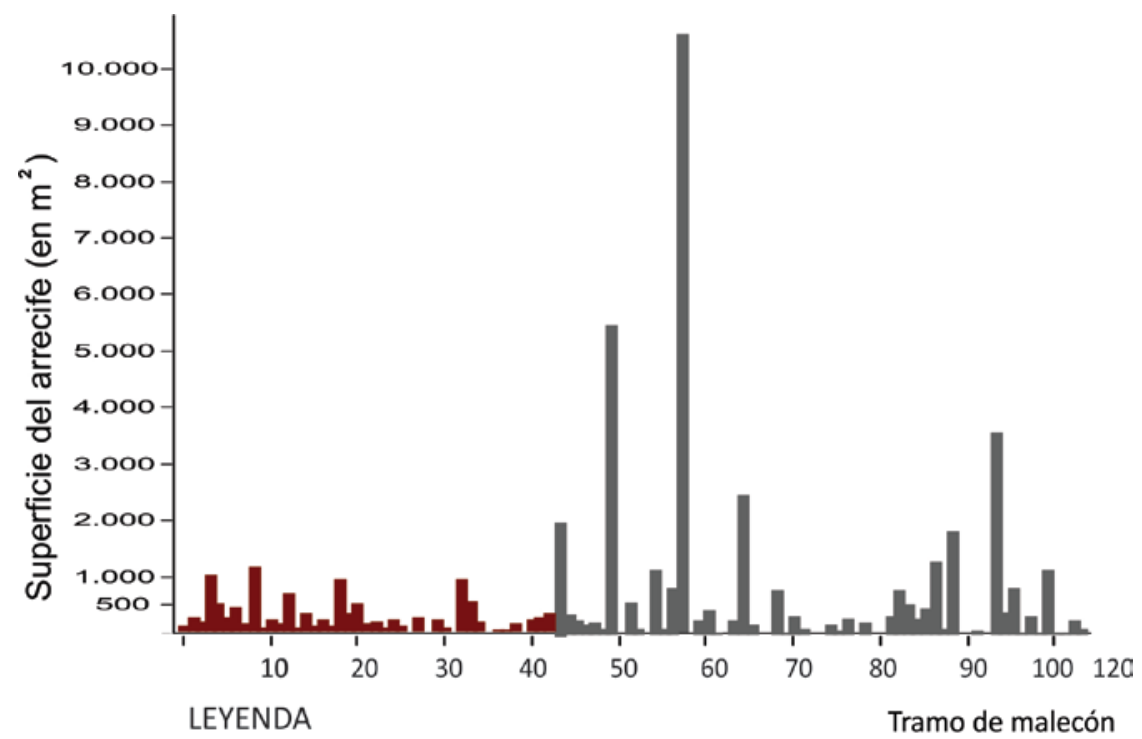

Superficie del arrecife (en $\mathrm{m}^{2}$ )

- Frente a zonas deterioradas del malecón

- Frente a zonas sin deterioro del malecón

Fuente: elaboración propia

d) Distancia del Malecón a la línea de costa

La Figura 11 muestra las diferencias en distancia del Malecón a la línea de costa en zonas deterioradas y no deterioradas, entendiéndose por línea de costa el límite del arrecife. Al calcular las estadísticas generales de este factor, que refleja la distancia que hay entre las zonas deterioradas y la línea de costa frente a ellas, los resultados muestran que, como promedio, el arrecife se encuentra a 6,73 $\mathrm{m}$ de las zonas deterioradas. Se aprecian zonas con una distancia mínima de $0 \mathrm{~m}$ (corresponden con zonas donde no hay arrecife) y otras donde la distancia máxima es de 19,92 m. Sin embargo, estas estadísticas no son iguales en todo el litoral. Las zonas deterioradas, en general, están a menos de $1 \mathrm{~m}$ de distancia de la costa o a cero metros de esta, que corresponden con las zonas donde el muro del Malecón es la prolongación de la línea de la costa, al no existir el arrecife emergido. Casi el $36 \%$ de las zonas deterioradas están a menos de 1 m de distancia de la línea de la costa y el $35 \%$ de ellas a cero metro, (en donde no existe el 
arrecife coralino emergido); si se suman estos dos valores, se obtendría que algo más del 70 \% de las zonas deterioradas están a menos de 1 m de distancia de la costa y sólo un 14 \% de ellas están a más de $16 \mathrm{~m}$. lo que nos refleja la importancia de esta variable en la protección de esta infraestructura.

Figura 11. Distancia del Malecón a la línea de costa en el sector estudiado



e) Altura del muro del Malecón

A pesar de que el muro del Malecón es una infraestructura continua, su altura no es la misma en toda su longitud. La altura mínima frente a las zonas con deterioro es de 1,02 m, mientras que la máxima es de 4,58 m; el valor promedio es igual a $1.72 \mathrm{~m}$. Sin embargo, si se analizan estas estadísticas con más detalle a través del histograma de frecuencia (Figura 12), se puede observar cómo la mayor parte de las zonas deterioradas (58 \% ) tienen frente a ellas una altura del muro por debajo de su valor promedio, mientras que un $41 \%$ de esta infraestructura tiene una altura del muro superior a su media aunque no muy alejada de esta en términos generales (Figura 12) lo que trae consigo que cualquier ola que se aproxime a estas alturas las sobrepasa con facilidad y salpique hacia el interior de la calle e inunda las zonas más bajas, sobre todo si proviene con una orientación similar a la de la costa, variable que será objeto de análisis a continuación. 
Figura 12. Altura del Malecón en las zonas deterioradas

y no deterioradas del sector estudiado

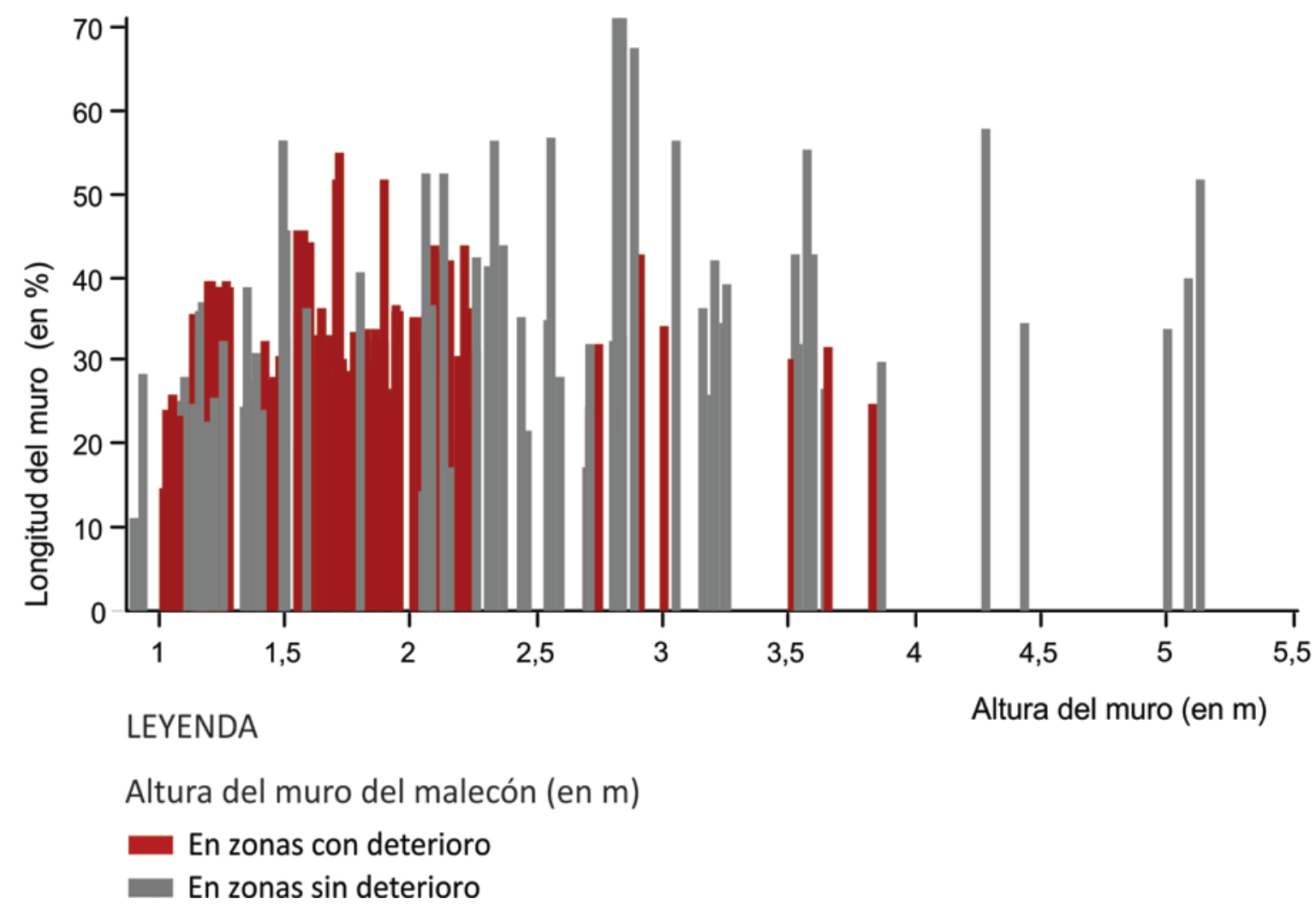

Fuente: elaboración propia

f) Orientación de la costa

La mayor parte de las zonas deterioradas tienen una orientación entre los $120^{\circ}$ y los $130^{\circ}$ (Figura 13). Esta orientación es muy similar a la dirección de donde provienen los frentes fríos, lo cual significa que el muro del Malecón, en las zonas deterioradas, tiene la misma orientación de los trenes de olas generados por estos eventos meteorológicos. El muro en este caso actúa como un obstáculo que frena el movimiento de las mismas provocando el choque constante del agua de mar en la estructura del Malecón y su salpicadura hacia el interior, lo que ocurre principalmente en las zonas con esta orientación. 
Figura 13. Frecuencia de la orientación de la costa en las zonas deterioradas y no deterioradas del sector estudiado

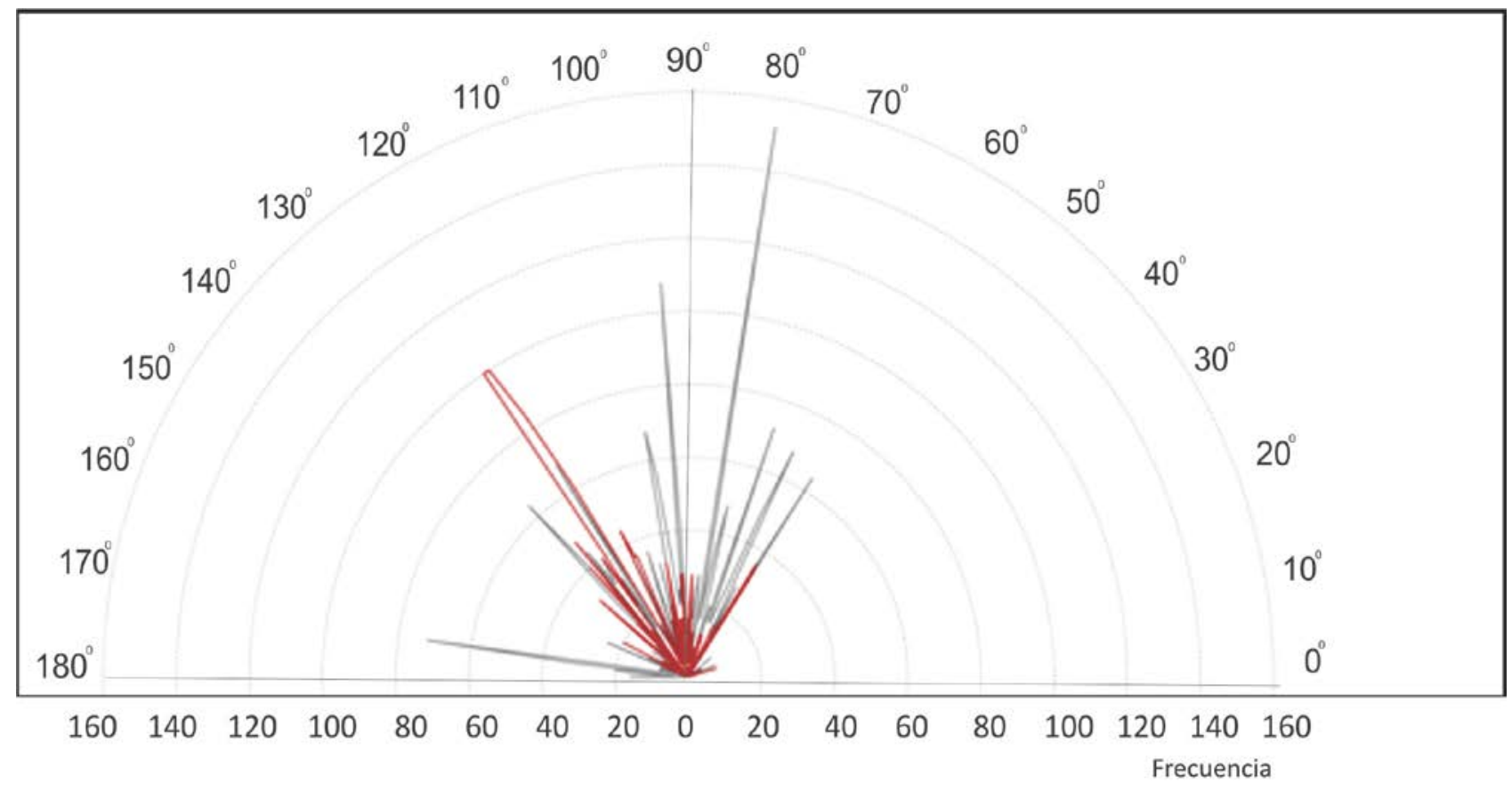

LEYENDA

Frecuencia (en número de veces)

- Zonas con deterioro

Zonas sin deterioro

$90^{\circ}$ Orientación de la costa (en grados)

Fuente: elaboración propia

g) Relación entre los factores y el deterioro del Malecón

Los resultados anteriores obtenidos a partir del análisis espacial muestran que hay evidencias de que en el deterioro influyen varias variables y unas variables más que otras, aspecto que se ha comprobado estadísticamente a partir del cálculo del coeficiente de correlación biserial puntual.

Los resultados de este coeficiente, incluidos en la tabla 5, muestran una alta correlación significativa entre la orientación de la costa y las zonas con deterioro. Ello significa que las zonas con deterioro están perfectamente orientadas respecto a los trenes de olas provocados por la llegada de los frentes fríos, sometiendo al Malecón a un incesante proceso de desgaste y meteorización mecánica y química. Con un menor nivel de significancia estadística, la distancia del Malecón a la línea de costa también ejerce cierta influencia, pues en los sectores del Malecón en los que existe cierta separación entre este y el mar, esta separación permite disipar en cierta medida la energía de los trenes de olas durante las temporadas de frentes fríos. 
Tabla 5. Resultados del cálculo del coeficiente de correlación biserial puntual $(P<0,05)$

\begin{tabular}{|l|c|}
\hline Variable & $\begin{array}{c}\text { Coeficiente de correlación } \\
\text { biserial Puntual }\end{array}$ \\
\hline Profundidad del mar & 0,16 \\
\hline Superficie del arrecife en la costa & $-0,22$ \\
\hline Distancia a la línea de la costa & 0,30 \\
\hline Altura del muro & $-0,24$ \\
\hline Orientación de la costa & 0,78 \\
\hline
\end{tabular}

Fuente: elaboración propia

\subsection{Diferenciación espacial del litoral habanero de acuerdo a la influencia de estos factores}

El empleo de los análisis de agrupamiento (cluster espacial) permitió diferenciar 2 zonas del Malecón habanero, teniendo en cuenta sus características y niveles de deterioro (Figura 14).

Figura 14. Vulnerabilidad de la zona según cluster espacial

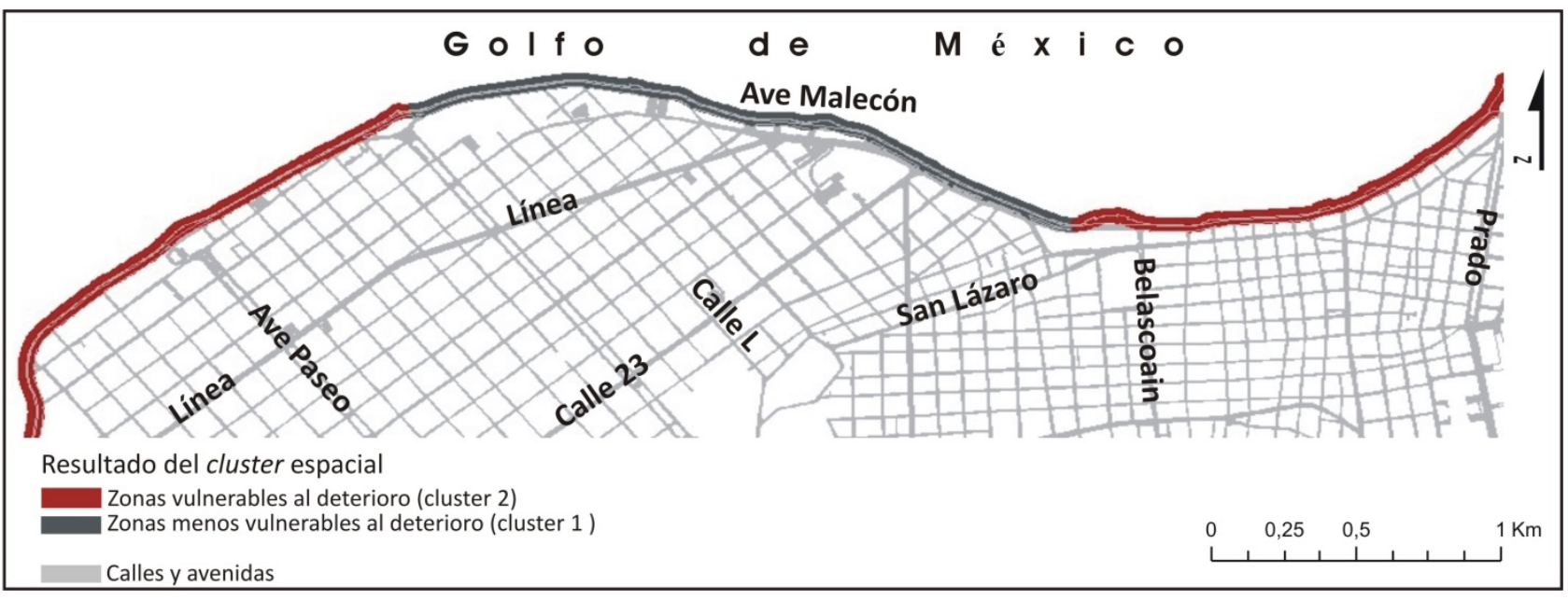

Fuente: elaboración propia

Las estadísticas revelan que el sector 1 concentra los mayores valores de deterioro en la infraestructura, entre las principales características del mismo se encuentran:

- La escasa superficie del arrecife costero o la inexistencia de este en muchas zonas frente al muro. Al mismo tiempo, resulta interesante que este es el sector cuya altura promedio del muro es menor en comparación con el otro sector.

- Existen abundantes superficies sumergidas con baja profundidad en la zona más próxima al muro del Malecón.

- Orientación en la costa predominantemente en la misma dirección de donde provienen los vientos de los frentes fríos. 
- Las zonas con deterioro se encuentran más próximas a la línea de la costa, la mayor parte de estas están a menos de $1 \mathrm{~m}$ de distancia de la costa o a cero metros de esta, lo que significa que las olas golpean directamente esta infraestructura.

El sector 2, por el contrario, presenta menos deterioro en su área, con sólo el 12.55\% de la superficie total, como consecuencia de:

- Tener una orientación en su costa con predominio al norte-noreste y una mayor superficie del arrecife frente a su costa.

- Tener una mayor distancia entre la línea de costa y el muro del Malecón.

- Abundancia de zonas sumergidas con una profundidad mayor en la costa en los 20 metros de distancia más próximos al muro lo que favorece que las olas alcancen menos altura en su cresta.

- Sorprende el hecho de que este sea el sector con una altura mayor del muro del Malecón cuando en realidad, es el menos expuesto a la acción del oleaje según las variables analizadas anteriormente.

Como resultado del Análisis de Agrupamiento se obtienen también una serie de estadísticas. En la Figura 15 se comparan las variables dentro de cada grupo en sí, y los diagramas de caja del resumen estadístico.

El primer conjunto de estadísticas que aparecen en negro son para los datos globales en cada variable. Cuanto mayor sea el valor R2 para una variable específica, mejor será ella en la discriminación entre las entidades, o sea que la variable Superficie del arrecife fue la más útil en este sentido.

Los diagramas de caja para estos datos globales muestran que la primera variable (Superficie del arrecife) presenta una gran dispersión y tiene una asimetría positiva en sus datos que es muy sesgada, lo que implica que el $25 \%$ de las observaciones comprendidas entre el primer y el segundo cuartil ocupen un menor tramo en la escala. Asimismo se ve que el bigote derecho de esta variable es más largo por corresponder a la cola más larga de la curva que presenta esta distribución, lo que sugiere una mayor dispersión de las observaciones hacia los valores más altos.

Para el caso de las otras cuatro variables (Distancia a la costa, Altura del muro, Orientación de la costa y Profundidad del mar), se observa una mayor concentración del $50 \%$ central de las observaciones, así como del total de sus datos, pues tanto la caja como los bigotes presentan una menor longitud, pero para el caso de la variable Orientación de la costa, se ve que el sesgo es negativo. 
Figura 15. Estadística del análisis de agrupamiento

a) Resultados estadísticos del agrupamiento de variables (cluster espacial)

\begin{tabular}{|c|c|c|c|c|c|c|}
\hline \multicolumn{7}{|c|}{ Group-Wise Summary } \\
\hline \multicolumn{7}{|c|}{ Overall Variable Statistics: Count $=300$, Std. Distance $=6240.2061$, SSD $=988.7307$} \\
\hline Variable & Mean & Std. Dev. & Min & Max & R2 & \\
\hline Superficie & 4272,5501 & 6146,8444 & 0,0000 & 14899,4004 & 0,5974 & $\bullet$ \\
\hline Altura del muro & 591,5919 & 1074,5265 & 0,0000 & 3518,4099 & 0,4575 & + \\
\hline $\begin{array}{l}\text { Orientación de } \\
\text { la costa }\end{array}$ & 1,7827 & 0,8229 & 0,8996 & 5,5842 & 0,3282 & $H+H+H$ \\
\hline $\begin{array}{l}\text { Distancia a } \\
\text { la costa }\end{array}$ & 105,5211 & 43,2080 & $-165,2180$ & 180,0000 & 0,2196 & +\# •대— \\
\hline Profundidad & $-3,6068$ & 1,2232 & -5.7723 & 0,0000 & 0,1016 & 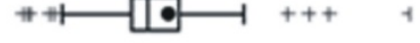 \\
\hline \multicolumn{7}{|c|}{ Group 1: Count $=118$, Std. Distance $=6229.8881$, SSD $=859.5764$} \\
\hline Variable & Mean & Std. Dev. & Min & $\operatorname{Max}$ & Share & \\
\hline $\begin{array}{l}\text { Superficie } \\
\text { del arrecife }\end{array}$ & 10172,9041 & 6100,5105 & 0,0000 & 14899,4004 & 1,0000 & \\
\hline Altura del muro & 1494,2221 & 1261,8664 & 0,0000 & 3518,4099 & 1,0000 & t \\
\hline $\begin{array}{l}\text { Orientación de } \\
\text { la costa }\end{array}$ & 2,3681 & 0,9731 & 1,0206 & 5,5842 & 0,9742 & ++ \\
\hline $\begin{array}{l}\text { Distancia a } \\
\text { la costa }\end{array}$ & 80,3752 & 54,4690 & $-165,2180$ & 127,6710 & 0,8484 & $-1+$ \\
\hline Profundidad & $-3,1226$ & 1,7007 & $-5,7723$ & 0,0000 & 1,0000 & $\longrightarrow++$ \\
\hline \multicolumn{7}{|c|}{ Group 2: Count $=182$, Std. Distance $=972.5650$, SSD $=129.1544$} \\
\hline Variable & Mean & Std. Dev. & Min & $\operatorname{Max}$ & Share & \\
\hline $\begin{array}{l}\text { Superficie } \\
\text { del arrecife }\end{array}$ & 447,0459 & 972,2673 & 0,0000 & 8120,0400 & 0.5450 & ఏ \\
\hline Altura del muro & 6,3701 & 10,0204 & 0,0000 & 67,6074 & 0,0192 & + \\
\hline $\begin{array}{l}\text { Orientación de } \\
\text { la costa }\end{array}$ & 1,4031 & 0,3688 & 0,8996 & 3,5052 & 0.5562 & +4 \\
\hline $\begin{array}{l}\text { Distancia a } \\
\text { la costa }\end{array}$ & 121,8245 & 21,8635 & 0,0000 & 180,0000 & 0.5214 & 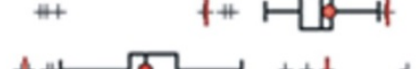 \\
\hline Profundidad & -3.9207 & 0,5836 & $-5,7115$ & $-1,2072$ & 0.7803 & $-1++t$ \\
\hline
\end{tabular}

b) Interpretación de los Diagramas de Caja

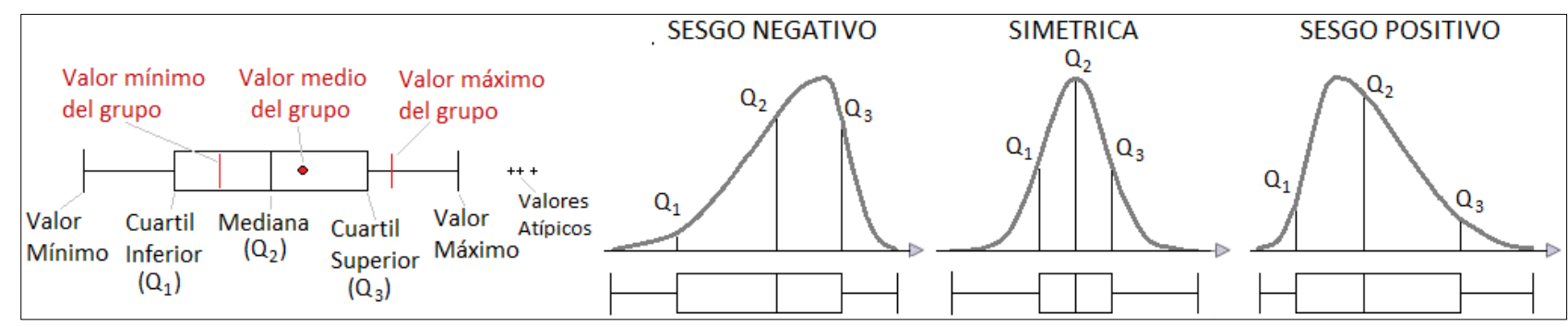

Fuente: elaboración propia

En el informe de la Figura 15 se puede ver que el grupo 1 (zonas sin deterioro) contiene el menor rango de valores en la variable Orientación de la costa con un $84 \%$, mientras que el grupo 2 (zonas con deterioro) presenta su menor rango en la variable Distancia a la costa.

Se puede observar que en el caso del grupo 2, que agrupa a las zonas con deterioro, el valor medio del grupo (puntos rojos), para tres de las variables, está muy próximo a la Mediana global, y solo para la cuarta variable, Orientación de la costa, cae sobre el cuartil superior. Sin embargo en 
el caso del grupo 1 (zonas sin deterioro), el valor medio del grupo (puntos grises), para las tres primeras variables, está por encima del cuartil superior, la tercera variable está por debajo del cuartil inferior, y la última variable también se encuentra por encima del $75 \%$ de los valores globales. Este primer grupo, tiene un rango más alto de valores en comparación con el otro.

\section{Conclusiones}

Con los resultados obtenidos, puede decirse que la hipótesis del trabajo ha quedado verificada, luego, existen diferentes grados de deterioro en el sector del Malecón de La Habana analizado, como consecuencia de un conjunto de variables geográficas que actúan de manera diferenciada en combinación con los eventos meteorológicos que afectan a este litoral. De este modo, se pueden apuntar las siguientes conclusiones:

I. Las principales manifestaciones de deterioro de esta infraestructura estuvieron relacionados con zonas de afloramiento de piedras en el hormigón de las aceras, huecos, grietas, cambios en la coloración del hormigón y oxidación y mal estado de la infraestructura de drenaje.

II. Se identificaron dos sectores del Malecón, con diferentes niveles de deterioro entre los cuales se destaca el sector 1 comprendido entre las calles 26 y $\mathrm{H}$ con cerca del $65 \%$ de las zonas deterioradas.

III. En este deterioro, influyeron un conjunto de variables geográficas que interactúan de manera diferente, ante los embates de los frentes fríos, en los meses de noviembre a mayo. La orientación de la costa en la misma dirección de las fuerzas predominante de los vientos de los frentes fríos, y la distancia del muro al límite norte del arrecife, están entre los factores que más inciden en el deterioro de esta infraestructura.

IV.Por último, las técnicas de procesamiento digital de imágenes de alta resolución permitieron realizar la cartografía del estado de las aceras del Malecón con una elevada precisión. Del conjunto de técnicas estudiadas, la de mejor resultado en la cartografía del estado del Malecón ha sido la técnica de clasificación orientada a objetos.

Agradecimientos: Los autores expresan su agradecimiento a Osvaldo Pérez López, investigador del Instituto de Meteorología de Cuba. También, los autores agradecen al Plan Propio de Investigación de la Universidad de Málaga-Campus Internacional Andalucía Tech, el soporte económico concedido para desarrollar esta investigación.

Declaración responsable: Las/os autoras/es declaran que no existe ningún conflicto de interés en relación a la publicación de este artículo. El trabajo de Ricardo Remond estuvo enfocado en la identificación de los factores o variables que influyen en el deterioro, su representación y análisis 
espacial y estadístico en el SIG, en particular las técnicas para el agrupamiento de variables (cluster) con vistas a determinar cuáles ejercen una mayor influencia sobre el deterioro y las zonas más vulnerables de estos espacios públicos. Al mismo tiempo se encargó de la redacción de este aspecto en el apartado metodológico y en el desarrollo del artículo. El trabajo de Karen Aguilar Múgica estuvo enfocado al desarrollo de la primera etapa de la metodología, a realizar la cartografía del deterioro del malecón habanero a partir del empleo de las técnicas de clasificación multiespectral y orientada a objetos, la generación de imágenes compuestas a través del cálculo de índices y la comprobación de los resultados de esta cartografía. Al mismo tiempo se encargó de la redacción de este aspecto en el apartado metodológico y en el desarrollo del artículo. Cindy Alfonso Álvarez se encargó de la caracterización del área de estudio, la identificación y caracterización de los factores que influyen en el deterioro y en la generación de la base de datos en el SIG con información sobre el deterioro utilizada para la comprobación de los resultados de cartografía obtenida con el procesamiento digital de las imágenes del satélite. Juan Francisco Martínez Murillo estuvo a cargo de la revisión y síntesis de los apartados: Historia y evolución del malecón habanero, fenómenos meteorológicos que lo afectan y características del área de estudio. Al mismo tiempo se encargó de la redacción de las conclusiones, la elaboración del resumen en español e inglés y la revisión del artículo y su ajuste a las normas de la revista. También se encargó de realizar las enmiendas a los señalamientos realizados por los revisores. 


\section{Bibliografía}

Chuvieco, E. (1996). Fundamentos de Teledetección espacial (3rd edition). Madrid: Rialp.

Clark Labs (2009). Segmentation and segment-based classification. In Clark Labs. Retrieved from https://clarklabs.org/segmentation-and-segment-based-classification/

Colectivo de Autores (2006). Regulaciones urbanísticas, Ciudad de La Habana. El Vedado, Municipio Plaza de la Revolución. La Habana: Ediciones Unión.

Comisión Nacional de Nombres Geográficos (2000). Diccionario Geográfico de Cuba. La Habana: Ediciones Geo.

Cué, J. (1987). Estadística (Segunda parte). La Habana: Editorial Pueblo y Educación.

Díaz, L. (1988). Determinación del oleaje característico de los fenómenos que han producido penetraciones del mar en la costa norte de La Habana (Trabajo de Diploma, Universidad de La Habana, Cuba) (Unpublished).

Eastman, J. R. (2012). Idrisi Selva Manual (volume 17). Worcester: Clark University.

Gezici, F., \& Hewings, G. J. (2007). Spatial analysis of regional inequalities in Turkey. European Planning Studies, 15(3), 383-403.

Jensen, R. (2007). Remote Sensing of the Environment. An Earth Resource Perspective (Second Edition). Upper Saddle River: University of South Carolina, Pearson Education.

Kulkarni, R., Paelinck, J., \& Stough, R. (2001). Spatial-Structural Relations among Technology Industrial Clusters. A Comparative Analysis of Metropolitan Regions in the US (ERSA conference papers, no. ersa01p228). CITY: European Regional Science Association.

Martori, J. C., \& Hoberg, K. (2008). Nuevas técnicas de estadística espacial para la detección de clusters residenciales de población inmigrante. Scripta Nova, XII(263). Retrieved from http://www.ub.edu/geocrit/sn/sn-263.htm

Moskal, M., Styers, D., \& Halabisky, M. (2011). Monitoring Urban Tree Cover Using Object-Based Image Analysis and Public Domain Remotely Sensed Data. Remote Sensing, 3, 2243-2262.

Navulur, K. (2007). Multiespectral Image Analysis Using the Object-Oriented Paradigm. New York: CRC Press.

Olaya, V. (2011). Sistemas de Información Geográfica. Retrieved from http://volaya.github.io/libro-sig/index.html

Oleire, S., Coenradie B., \& Kleinschmit B. (2011). An Object-Based Classification Approach for Mapping Migrant Housing in the Mega-Urban Area of the Pearl River Delta (China). Remote Sensing, 3, 1710-1723. 
Pedregal, B., Torres, F. S., \& Zoido, F. (2006). Propuesta metodológica para la medición del desarrollo y las desigualdades territoriales. Aplicación al territorio andaluz. Scripta Nova, X(220). Retrieved from http://www.ub.edu/geocrit/sn/sn-220.htm

Pérez, P., Casals, R., \& Díaz, L. (2001). Análisis de los fenómenos meteorológicos que provocaron penetraciones del mar en el Malecón habanero. Revista Cubana de Meteorología 8(1), 50-58.

Rodríguez, J. L. (2009). Lo VEDADO de El Vedado. La Habana: Editorial GDIC.

Sánchez, M. (2008). Análisis espacial de datos y turismo: nuevas técnicas para el análisis turístico. Una aplicación al caso extremeño. Revista de Estudios Empresariales, 2, 48-66.

Seco, R. (2002). Teledetección aeroespacial. La Habana: Editorial Félix Varela.

Vázquez, A. (2013). Malecón versus frente frío. In Quinqué. Proyecto cubano de fotografía [Blog entry]. Retrieved from http://www.quinquecuba.com/fotos-malecon-vs-frente-frio/

Wall, P. A., \& Devine, O. J. (2000). Interactive analysis of the spatial distribution of disease using a geographic information systems. Journal of Geographical Systems, 2(3), 243-256.

Weng, Q. (2012). Urban Remote Sensing. New York: CRC Press. 